\title{
Morfologia do coração e dos vasos da base do pinguim-de-magalhães (Spheniscus magellanicus)
}

[Morphology of heart and vessels of the cardiac base in Magellanic penguin (Spheniscus magellanicus)]

D.F. Guimarães, A.P.M. Carvalho*, J. Ywasaki, C.D. Neves, A.B.F. Rodrigues, L.S. Silveira

Universidade Estadual do Norte Fluminense Darcy Ribeiro - Campos dos Goytacazes, RJ

\section{RESUMO}

O pinguim-de-magalhães é uma ave marinha de porte médio, de origem do hemisfério sul, com grandes colônias próximas à Patagônia. Em certas épocas do ano, alguns exemplares aparecem no litoral brasileiro, devido ao desvio de rotas de caça, e alguns indivíduos não conseguem retornar por debilidades na saúde. Foram utilizados 34 exemplares de Spheniscus magellanicus que vieram a óbito no litoral do estado de Espírito Santo. O presente estudo analisou a morfologia de câmaras e paredes cardíacas, valvas e artérias da base. Os fragmentos dessas regiões foram analisados histologicamente com coloração hematoxilina-eosina (HE) e Tricrômico de Gomori (TG), além da coloração Picrosirius Red (PSR) sob luz polarizada, visando observar, principalmente, a composição do tipo de colágeno existente em cada região descrita. Entre os 34 exemplares, nenhum apresentou discrepância em relação a sua morfologia. A tipificação do colágeno dessas regiões pelas colorações TG e PSR sob luz polarizada demonstrou a presença do colágeno tipo I em maior evidência que o tipo III, encontrada na maioria das estruturas, o que atribuiu a aparência avermelhada intensa a quase todas elas. Pode-se concluir que a anatomia cardíaca do pinguim-de-magalhães é semelhante à de outras aves, com predominância do colágeno do tipo I.

Palavras-chave: pinguim-de-magalhães, morfologia cardíaca, colágeno

\begin{abstract}
Magellanic penguin is medium-sized seabird originated from southern hemisphere with colonies near Patagonia. At certain times of the year in Brazilian coast, a few penguins lose their hunting routes and can't return because they are very sick. Thirty-four penguins died in Espírito Santo's coast. This study analyzed the cardiac morphology and morph metric of heart chambers and walls, valves, and arteries of the cardiac base. These parts were analysed and stained by Hematoxilin and eosin and Gomori's trichrome. Mainly targeting the collagen's composition in each described part the Picru-sirius Red's stain under polarized light was used. Among thirty-four penguin hearts, none presented discrepancy in morphology, they were all very similar. The characterization of collagen by Picrusirius Red stain highlighted type 1 collagen in comparison to type 3 collagen in most structures, giving a more reddish appearance in almost of them. In conclusion, the cardiac anatomy of the Magellanic Penguin is similar to that of other birds, with a predominance of type I collagen.
\end{abstract}

Keywords: magellanic penguin, cardiac morphology, collagen

Recebido em 13 de março de 2017

Aceito em 9 de junho de 2017

* Autor para correspondência (corresponding author)

E-mail: annapmcarvalho@gmail.com 


\section{INTRODUÇÃO}

A espécie Spheniscus magellanicus, mais conhecida como pinguim-de-magalhães, habita toda a costa da América do Sul (Williams, 1995). No inverno, essas aves migram para a costa brasileira, em direção ao Sul e Sudeste, à procura de alimento, no entanto há relatos de animais que alcançaram o Nordeste (Silva-Filho e Ruoppolo, 2006; Brandão et al., 2011; Petry et al., 2012).

São aves de médio porte, com cerca de 70 centímetros de altura e peso médio de $5 \mathrm{~kg}$. Os olhos, o bico e as patas são negros. Sua plumagem é negra no dorso e nas asas e branca na região abdominal e na cervical ventral. A maior parte dos exemplares possui uma faixa branca na cabeça, que passa por cima das sobrancelhas, contorna as orelhas e se une no pescoço, e outra faixa negra e fina em seu peitoral em formato de ferradura (I.P.C.W.G, 2002). Essa espécie vive em torno de 25 anos (Brandão et al., 2011; Petry et al., 2012).

Trabalhos sobre morfologia de pinguins são escassos, apesar da importância para o conhecimento anatômico e biológico. Dados referentes à anatomofisiologia dessa espécie de vida livre são de grande relevância, pois avaliam a estrutura, a arquitetura e o formato dos órgãos, auxiliando na compreensão de mecanismos fisiológicos e biológicos.

O presente estudo objetivou descrever e avaliar morfologicamente o coração e os vasos basais do pinguin-de-magalhães (Spheniscus magellanicus).

\section{MATERIAL E MÉTODOS}

Foram utilizados 34 espécimes de pinguins-demagalhães que vieram a óbito, cedidos pelo Instituto Orca, provenientes do litoral do estado do Espírito Santo (Brasil).

Após a necropsia das aves, os corações foram retirados da cavidade celomática, junto com os vasos da base cardíaca, e imediatamente imersos em solução de formaldeído tamponado neutro a $10 \%$, em posição anatômica durante 48 horas, com o intuito de não perder sua conformação. Após estarem completamente fixadas, as peças foram mensuradas e dissecadas no Laboratório de Morfologia e Patologia Animal (LMPA), do Hospital Veterinário da Universidade Estadual do Norte Fluminense Darcy Ribeiro (UENF), em Campos dos Goytacazes.

Histologicamente, avaliaram-se a valva atrioventricular esquerda junto com as cordas tendíneas, a valva atrioventricular direita, a valva aórtica, a valva pulmonar e o corte transversal do terço médio cardíaco. Os vasos da base do coração avaliados foram a aorta, a artéria pulmonar e a artéria braquiocefálica. As colorações utilizadas foram a hematoxilinaeosina (HE), como base para as avaliações arquitetônicas, o Tricômio de Gomori (TG), para diferenciar as regiões compostas de tecido conjuntivo, e coloração por Picrosirius Red (PSR), para determinar os tipos de colágeno I e III encontrados em cada fragmento.

\section{RESULTADOS E DISCUSSÃO}

O sistema cardiovascular varia nas diversas espécies de vertebrados, devido às adaptações ocorridas durante a evolução das espécies (Franklin e Axelsson, 1994; Wyneken, 2001), contudo, sob o ponto da anatomia descritiva, o coração do pinguim-de-magalhães não apresentou grandes diferenças em relação a outras aves.

O coração do pinguim-de-magalhães, assim como o de todas as aves, situa-se na porção superior da cavidade celomática (Fig. 1A), cranial aos pulmões e lóbulos hepáticos. Possui uma base maior, onde estão seus principais vasos, um corpo dividido em quatro câmaras, dois ventrículos e dois átrios, e um ápice formado pela porção mais distal da câmara ventricular esquerda.

$\mathrm{Na}$ sua base, contém a aorta, a artéria mais calibrosa e de parede mais espessa. Sua primeira porção situa-se cranial e central à base, com desvio para a direita no seu trajeto caudal. A aorta se ramifica nas artérias coronárias direita e esquerda. 


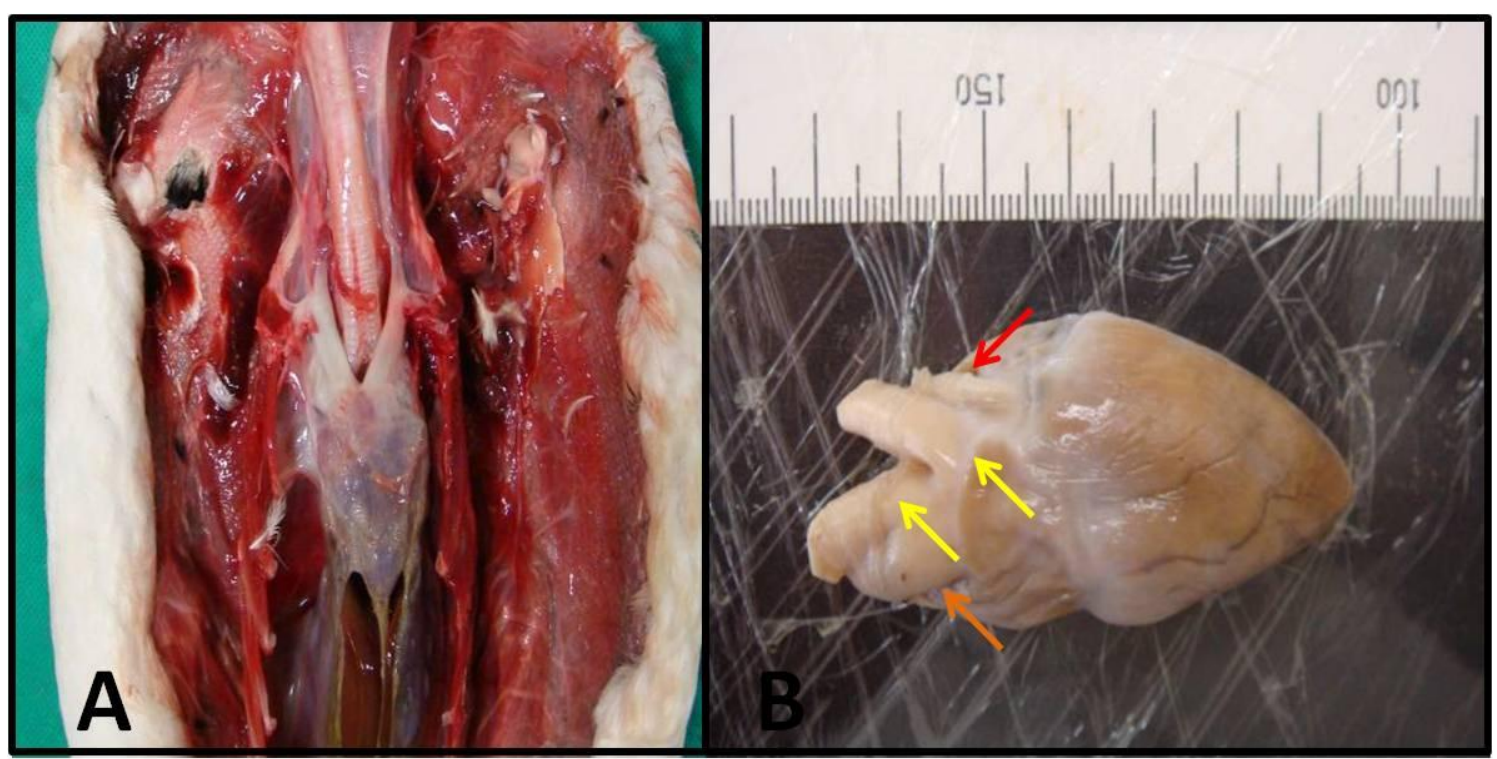

Figura 1. A) Fotomacrografia demonstrando a sintopia do coração de pinguim-de-magalhães na cavidade celomática envolto pelo pericárdio. B) Coração de pinguim-de-magalhães, com as artérias: aorta (seta laranja), braquiocefálicas (setas amarelas) e pulmonar (seta vermelha).

Conforme relatado em outros vertebrados, a aorta origina-se do ventrículo esquerdo e situa-se na base do coração. Seus primeiros ramos são a artéria coronária esquerda, situada à esquerda, entre o tronco pulmonar e a aurícula esquerda, e a coronária direita, entre o tronco pulmonar e a aurícula direita. As coronárias se ramificam em ramos superficiais e profundos e estes são responsáveis pelo suprimento do miocárdio. (Dyce, 2010).

A segunda ramificação da aorta são as artérias braquiocefálicas direita e esquerda (Fig. 1B), que possuem paredes espessas, com proporções próximas da aorta. As artérias braquiocefálicas formam um "V" inclinado para a esquerda da aorta, seguindo em direção ao pescoço. Uma característica típica das aves, e observada no pinguim-de-magalhães, é a existência de um tronco braquiocefálico, antes da bifurcação nas duas artérias, diferentemente do que ocorre no peru, uma ave doméstica que não apresenta esse tronco, assim como o avestruz (Dyce et al., 2010; Soares et al., 2010). As demais artérias e vasos menos calibrosos são semelhantes às outras aves (Ghoshal, 1972).

A última artéria da base cardíaca é a artéria pulmonar, situada cranial e à esquerda da artéria braquiocefálica esquerda (Fig. 1B). Possui parede delgada, com origem na saída do ventrículo direito, seguindo em direção caudal.

O avestruz (Struthio camelus) apresenta maior grau de ramificações e anastomoses no sistema arterial coronariano do que os pinguins. Possivelmente por ser uma ave de grande porte e corredora, supõe-se que o aumento da musculatura cardíaca possa ter levado ao aumento das ramificações coronarianas (Rodrigues et al., 1999).

O coração é formado por quatro câmaras, sendo duas atriais e duas ventriculares, subdividas em um átrio e um ventrículo direito e um átrio e um ventrículo esquerdo. As câmaras direitas são separadas pela valva atrioventricular direita, sendo uma aba muscular nas aves (Fig. 2A). A valva tem sua origem na borda do óstio atrioventricular direito e insere-se na lateral da parede ventricular direita. As câmaras esquerdas são separadas pela valva atrioventricular esquerda, formada por três valvas, com origem no contorno do óstio atrioventricular esquerdo. As valvas estão ligadas por um conjunto de três a quatro cordas tendíneas em cada uma delas, que se inserem nos músculos papilares, encontrados no interior do ventrículo esquerdo (Fig. 2B). Na saída do ventrículo esquerdo, encontra-se a valva aórtica, formada por três valvas semilunares. $\mathrm{Na}$ saída do ventrículo direito, há a valva pulmonar, 


\section{Guimarães et al.}

que possui três valvas semilunares (Fig. 2C), assim como a aorta.

As duas câmaras atriais possuem paredes delgadas separadas pelo septo interatrial, também de parede fina. $\mathrm{O}$ interior dos átrios apresenta pequenos feixes musculares, denominados músculos pectíneos.
A câmara ventricular direita tem o formato de lua crescente, com a aba muscular, em sua grande parte, dentro do seu interior. A câmara ventricular esquerda apresenta um lúmen estreito em relação à câmara direita, com parede mais espessa, sendo possível observar as trabéculas carnosas na parede interna, o que corrobora Soares et al. (2010). Entre as duas câmaras, situa-se o septo interventricular, que é espesso, diferente do septo interatrial.

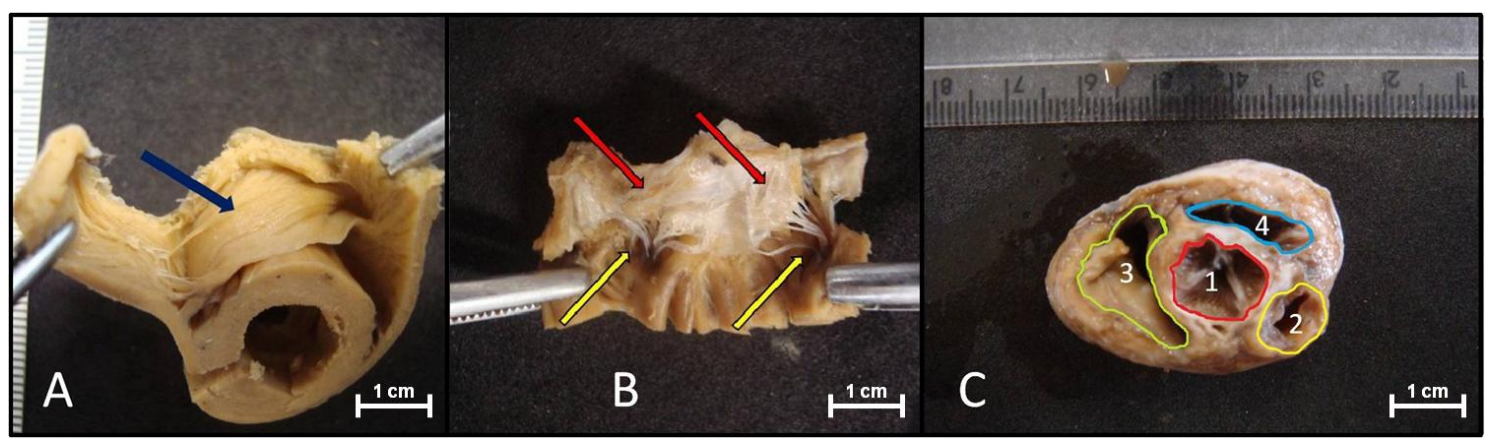

Figura 2. Fotomacrografia ex situ A) Valva atrioventricular direita, formada por uma aba muscular oriunda do ventrículo direito (seta azul). B) Valva atrioventricular esquerda (setas vermelhas) com suas cordas tendíneas (setas amarelas) inseridas nos músculos papilares. C) Corte do coração na altura da base, demonstrando a valva aórtica (1), a valva pulmonar (2), a valva atrioventricular direita (3) e a valva atrioventricular esquerda (4).

No fragmento da valva atrioventricular esquerda, há tecido muscular para sustentação da valva, juntamente com tecido conjuntivo ligando-se ao tecido mixomatoso. O tecido mixomatoso estava presente tanto nas valvas quanto nas cordas tendíneas (Fig. 3A).

$\mathrm{Na}$ valva atrioventricular direita, que é formada por aba muscular, em corte longitudinal, há dois grupos musculares, o mais interno com fibras longitudinais, e o grupo da periferia com fibras transversais. Na região mais dorsal da aba, foi encontrado, na curvatura, tecido conjuntivo frouxo com presença de feixes de nervos e vasos de menor calibre.

$\mathrm{Na}$ valva aórtica, foram observados fragmentos musculares, que dão grande sustentação à valva. Logo em seguida, existem dois "pilares" para a valva, dois fragmentos de cartilagem hialina, um de cada lado, onde se visualiza, na sequência, a valva semilunar, composta por tecido mixomatoso. Há também a presença de tecido conjuntivo na periferia da cartilagem hialina (Fig. 3B) (Junqueira e Carneiro, 2004).
A aorta (Fig. 3C) e a artéria braquiocefálica podem ser consideradas grandes artérias ou artérias elásticas, compostas por camada adventícia, com grande quantidade de camadas musculares lisas e a presença da camada íntima, composta por endotélio.

A artéria pulmonar pode ser classificada como artéria média ou muscular. Por não ter uma adventícia evidente, possui grande número de camadas musculares e a presença de camada íntima (Junqueira e Carneiro, 2004).

O fragmento do tecido muscular estriado cardíaco apresenta uma camada fina de pericárdio na periferia, bem unida ao tecido muscular, com disposição de fibras em sentido transversal; internamente, fibras musculares se dispõem em sentido longitudinal. Antes do endocárdio, mais interno a essa camada longitudinal, as fibras tornam-se transversais novamente (Fig. 4). 


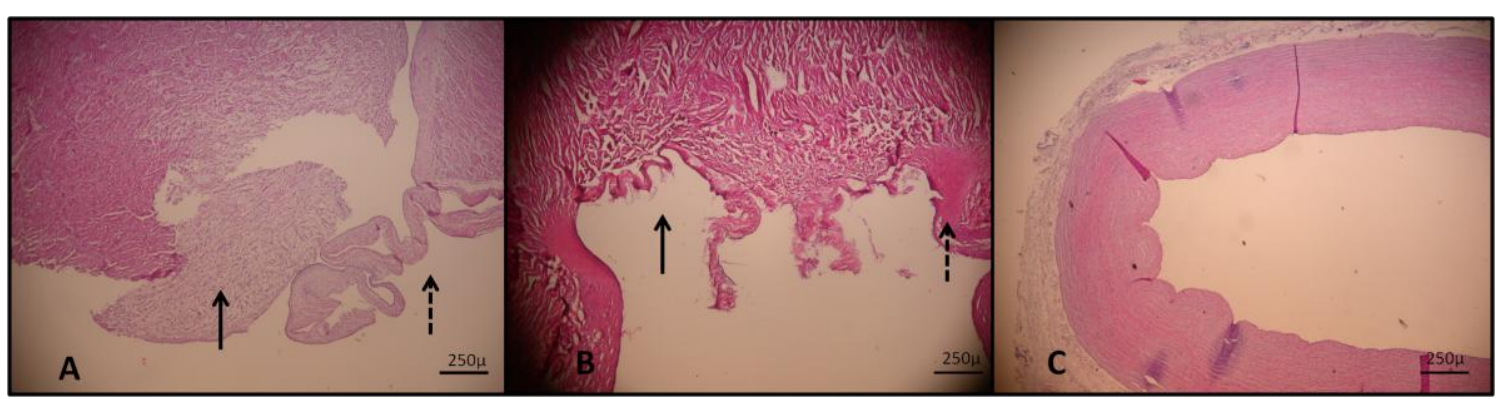

Figura 3. Cortes histológicos de coração de pinguim-de-magalhães corados por hematoxilina-eosina (HE). A) Valva atrioventricular esquerda (seta simples) com corda tendínea (seta tracejada). B) Valva semilunar aórtica (seta preta) com cartilagem hialina (seta tracejada). C) Aorta.

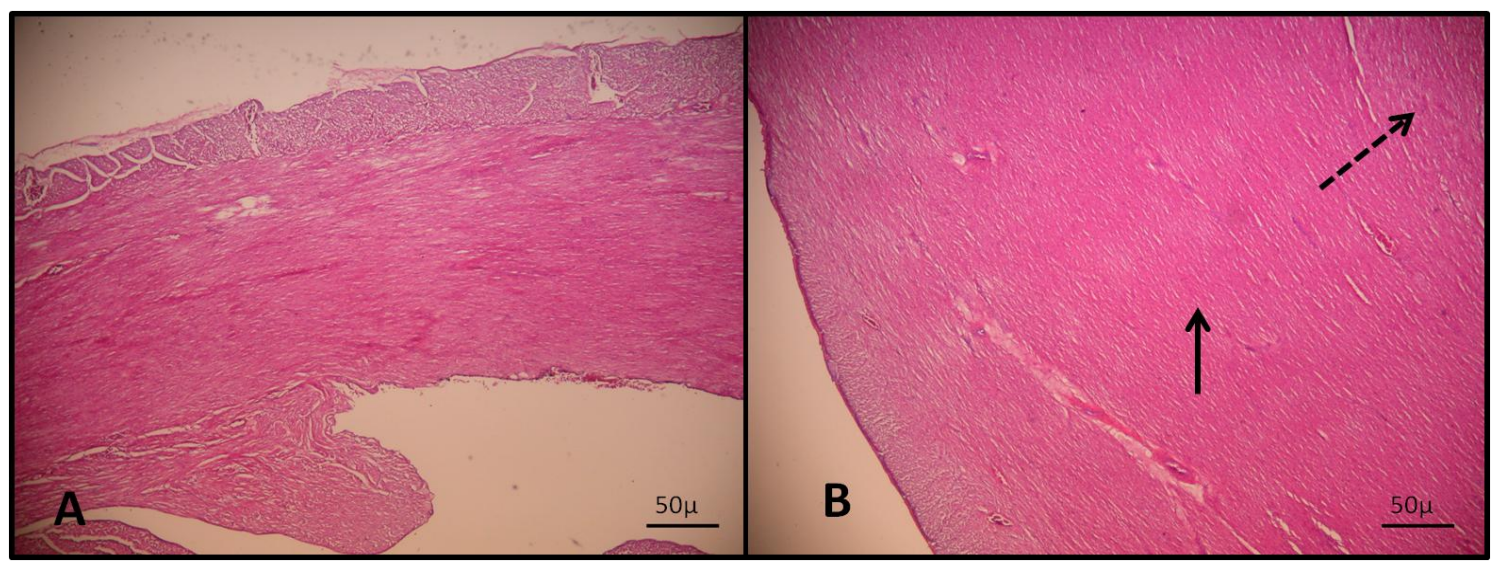

Figura 4. Cortes histológicos de coração de pinguim-de-magalhães corados por hematoxilina-eosina (HE). A) Musculatura cardíaca, corte terço médio. B) Musculatura cardíaca, direções das fibras musculares: transversais (seta tracejada) e longitudinais (seta simples).

No fragmento da valva atrioventricular esquerda, foi encontrado tecido muscular para sustentação, junto com tecido conjuntivo ligando-se ao tecido mixomatoso (Fig. 5A). Entre a camada muscular e a mixomatosa, há a presença de tecido conjuntivo frouxo, entremeado com fibras musculares, sendo o tecido conjuntivo corado em tom de azul escuro, e as fibras musculares de vermelho (Fig. 5B). O tecido mixomatoso estava presente tanto nas valvas quanto nas cordas tendíneas. A descrição histológica é similar àquela descrita para a valva atrioventricular esquerda de avestruzes (Abidu-Figueiredo et al., 2013).

A valva atrioventricular direita, formada por uma aba muscular estriada cardíaca, apresenta dois grupos musculares em corte longitudinal: o interno segue com fibras longitudinais e o grupo externo segue com fibras transversais. Na região mais dorsal da aba, há tecido conjuntivo frouxo com presença de feixes nervosos e vasos pouco calibrosos.
$\mathrm{Na}$ valva aórtica, foram encontrados fragmentos musculares para sua sustentação, com presença de dois fragmentos de cartilagem hialina, um de cada lado. Essa valva é composta por tecido mixomatoso e tecido conjuntivo na periferia, unindo-se à cartilagem hialina.

O fragmento do tecido muscular, com corte transversal no terço médio, possui uma camada fina de pericárdio em sua periferia e, unindo-se a ele, há tecido muscular com disposição de fibras em sentido transversal. Internamente, as fibras musculares se dispõem em sentido longitudinal e, na camada mais interna antes do endocárdio, as fibras tornam-se transversais novamente. Há a presença de fáscias de adesão formadas de tecido conjuntivo, responsáveis por ligar as fibras musculares cardíacas. Na região do endocárdio, há forte presença do tecido conjuntivo em toda sua extensão (Fig. 5C). 


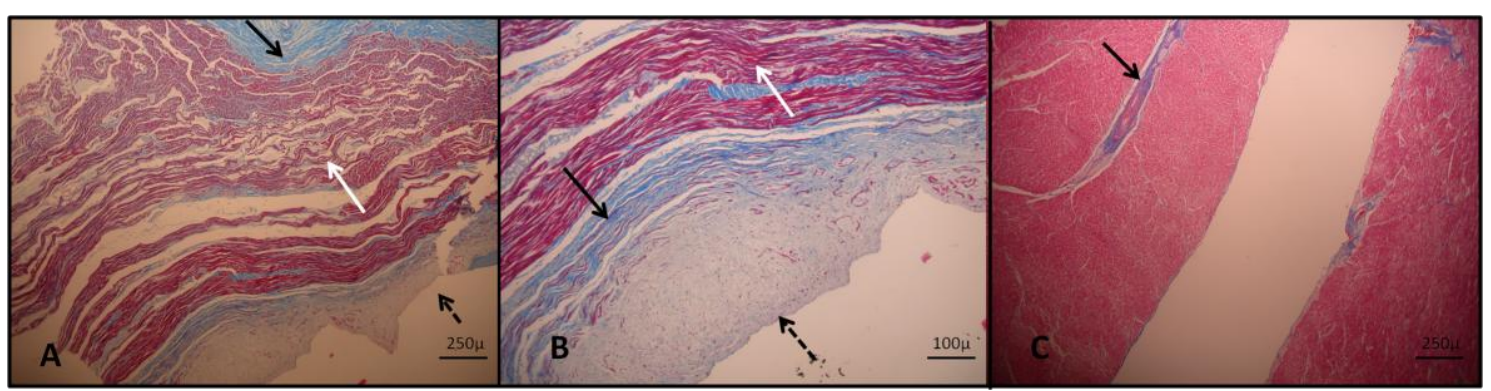

Figura 5. Cortes histológicos dos fragmentos de valva atrioventricular de pinguim-de-magalhães pela coloração tricrômico de Gomori. A) Valva atrioventricular esquerda: tecido mixomatoso (seta tracejada), tecido conjuntivo (seta preta), tecido muscular (seta branca). B) Valva atrioventricular esquerda: tecido mixomatoso (seta tracejada), tecido conjuntivo (seta preta), tecido muscular (seta branca). C) Fibras musculares (vermelho), endocárdio com tecido conjuntivo (azul), arteríola com tecido conjuntivo em azul (seta preta).

Picrosirius red (PSR) é uma técnica de coloração histológica, comumente usada para visualizar colágeno em cortes de tecido embebidos em parafina. No PSR, o colágeno aparece na cor vermelha em microscopia de luz (Vogel et al., 2015). O Picrosirius Red, em contraste com colorações mais tradicionais como Tricrômico de Masson, tem uma seletividade que o torna ideal e superior para a coloração e quantificação de colágeno (Junqueira et al., 1979).

O estudo pela técnica do Picrosirius Red sob luz convencional e polarizada obteve resultados com predominância de fibras de colágeno tipo I sob a maioria dos tecidos visualizados, as quais são consideradas mais maduras e fortemente birrefringentes, na cor vermelha à dourada, bem como algumas estruturas com fibras de colágeno tipo III, as quais são consideradas imaturas e com fraca birrefringência sob a luz polarizada, na cor esverdeada, conforme descrito em literatura (Kamath et al., 2013).

A valva atrioventricular esquerda apresentou, na região do tecido mixomatoso, fibras de colágeno de cor esverdeada, sendo classificadas como colágeno do tipo III, por serem fibras mais delgadas e fracamente birrefringentes (Fig. 6A, B, C, D). A valva atrioventricular direita, formada por musculatura estriada cardíaca, segue um padrão em toda sua periferia de colágeno tipo I e, no interior, apresenta uma distribuição homogênea dos colágenos de tipo I e III. A presença dos dois tipos de colágeno também foi relatada na valva atrioventricular direita de avestruzes (Abidu-Fugueiredo et al., 2013). $\mathrm{Na}$ face voltada para o interior atrioventricular, foi observado um tecido conjuntivo mais espesso que o encontrado na face voltada para a parede ventricular direita (Fig. 6E, F, G, H).

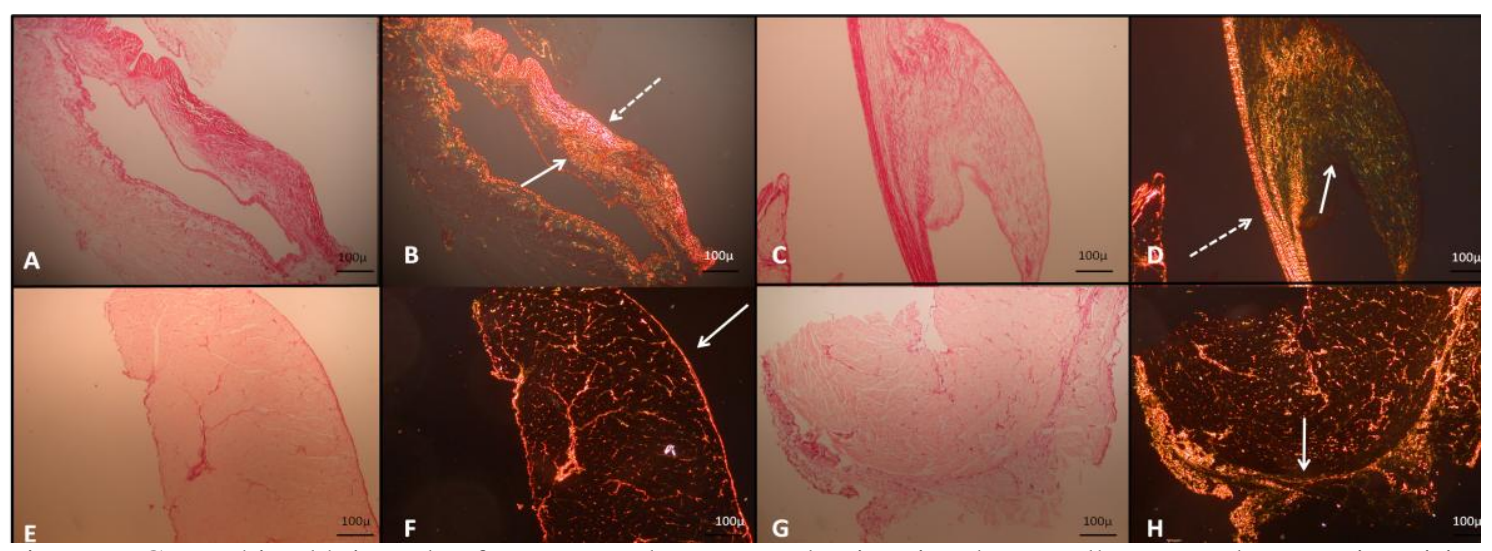

Figura 6. Cortes histológicos dos fragmentos de coração de pinguim-de-magalhães corados por picrosirius red sob luz convencional e picrosirius red sob luz polarizada. A, B, C e D) Valva atrioventricular esquerda com tecido mixomatoso (fibras esverdeadas, seta branca) e tecido conjuntivo (fibras vermelhas, seta tracejada). E, F, G e H) Valva atrioventricular direita, tecido conjuntivo na periferia (seta branca). 
A cartilagem hialina da valva aórtica apresenta fibras colágenas do tipo I, bem vermelhas e maduras, com forte birrefringência. $\mathrm{Na}$ valva semilunar, as fibras visualizadas são do tipo III, apresentando fraca birrefringência, assim como a região mixomatosa da valva atrioventricular esquerda (Fig. 7A, B, C, D). Nas artérias, foram encontrados resultados semelhantes naquelas que possuem adventícia bem demarcada, como a aorta e a braquiocefálica (Fig. 7E, F). Entre as fibras musculares, foram observadas fibras fortemente birrefringentes, vermelhas e maduras, do tipo I. O endotélio também apresentou, em sua maioria, fibras do tipo I e poucas fibras do tipo III.
Na musculatura cardíaca, tanto o endocárdio como o pericárdio apresentaram os dois tipos de colágeno, porém com o do tipo I mais presente, o que se deve à presença do tecido conjuntivo (Fig. 7G, H). Whittaker et al. (1994) e Hildebrando et al. (2011) também relataram a presença os dois tipos de fibras de colágeno na musculatura cardíaca em humanos e cães, respectivamente. As fibras de colágeno desempenham um papel importante na manutenção da integridade estrutural dos tecidos saudáveis (Junqueira e Carneiro, 2004).

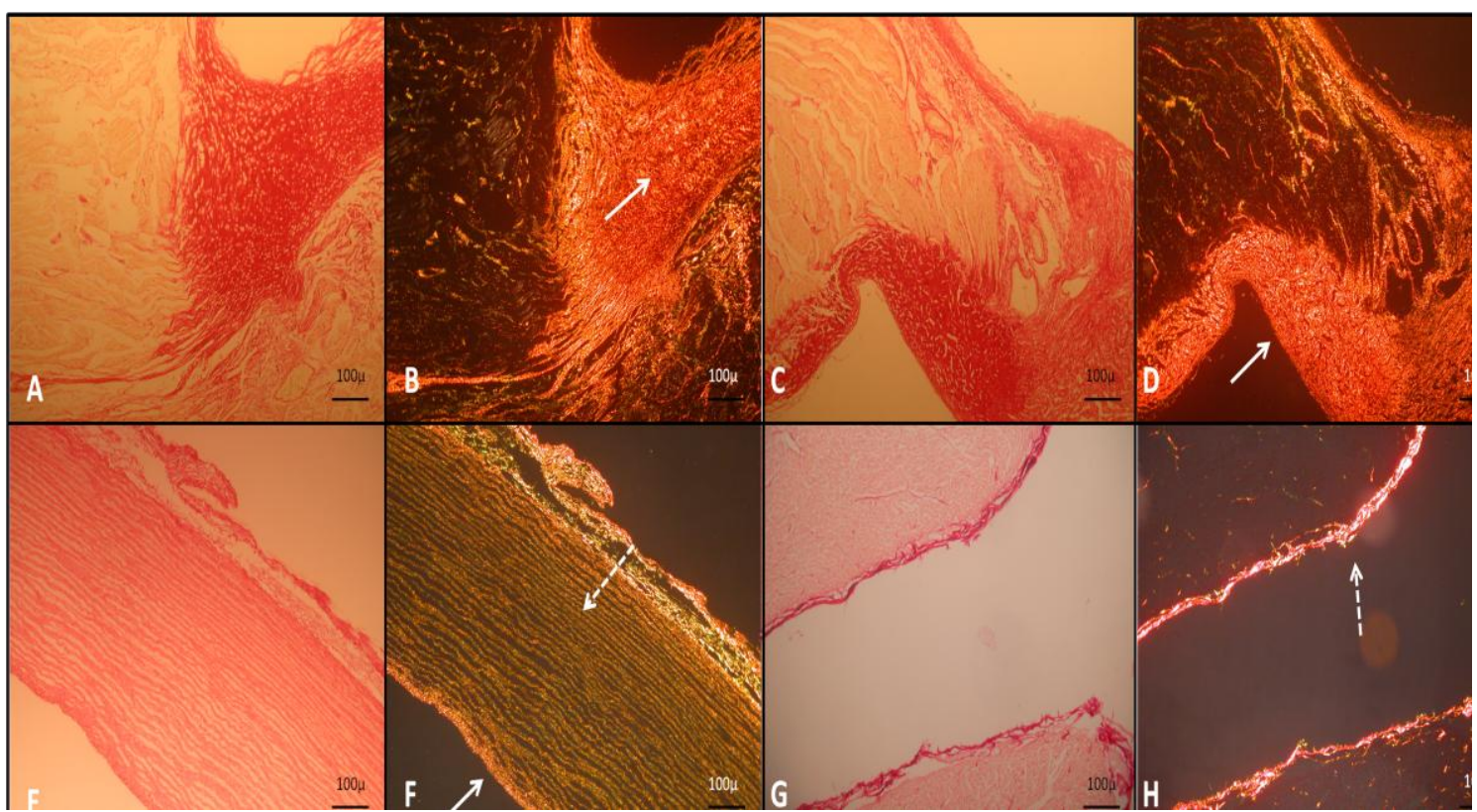

Figura 7. Cortes histológicos dos fragmentos de coração de pinguim-de-magalhães corados por picrosirius red sob luz convencional e sob luz polarizada. A, B, C e D): Valva aórtica com ênfase na cartilagem hialina (fibras vermelhas a douradas, seta branca). E e F): Aorta (fibras vermelhas entre a musculatura lisa, seta tracejada) com endotélio em evidência (seta branca). G e H) Endocárdio com a presença de tecido conjuntivo e fibras de Purkinje (seta tracejada).

\section{CONCLUSÃO}

A anatomia do coração e das artérias da base cardíaca do pinguim-de-magalhães é semelhante à de outras aves, anteriormente descritas na literatura. Pela avaliação microscópica para determinação do colágeno, o colágeno do tipo I foi aquele com maior concentração, seguido pelo colágeno do tipo III.

\section{REFERÊNCIAS}

ABIDU-FIGUEIREDO, M.; SANTOS, C.M.; PEREIRA-SAMPAIO, M.A.; CHAGAS, M.A. Morphological aspects of atrioventricular valves in the ostrich (Struthio camelus). Biotemas, v.26, p.203-208, 2013.

BRANDÃO, M.L.; BRAGA, K.M.; LUQUE, J.L. Marine debris ingestion by Magellanic penguins, Spheniscus magellanicus (Aves: Sphenisciformes), from the Brazilian coastal zone. Mar. Pollut. Bull., v.62, p.2246-2249, 2011. 
DYCE, K.M.; SACK, W.O.; WENSING, C.J.G. Tratado de anatomia veterinária. 4.ed. Rio de Janeiro: Guanabara Koogan, 2010. 844p.

FRANKLIN, C.; AXELSSON, M. The intrinsic properties of an in situ perfused crocodile heart. $J$. Exp. Biol., v.186, p.269-288, 1994.

GHOSHAL, N.G. Coração e artérias de carnívoros. In: SISSON, S.; GROSSMAN, J.D.; GETTY, R. Anatomia dos animais domésticos. 5.ed. Rio de Janeiro: Guanabara Koogan, 1972. v.2, p.1497-1550.

HILDEBRANDO, B.G.; BOMBONATO, P.P.; MACCHIARELLI, G. et al. Structural arrangement of the cardiac collagen fibers of healthy and diabetic dogs. Microsc. Res. Tech., v.74, p.1018-1023, 2011.

JUNQUEIRA, L.C.; BIGNOLAS, G.; BRENTANI R.R. Picrosirius staining plus polarization microscopy, a specific method for collagen detection in tissue sections. Histochem. J., v.11, p.447-455, 1979

JUNQUEIRA, L.C.U.; CARNEIRO, J. Histologia básica. 10.ed. Rio de Janeiro: Guanabara Koogan, 2004. 488p.

KAMATH, V.V.; SATELUR, K.; KOMALI, Y.; KRISHNAMURTHY, S.S. Image analyses of collagen types and thickness in oral sub mucous fibrosis stained with picrosirius red under polarizing microscope. $J$. Orofacial Sci., v.5, p.123-127, 2013.

I.P.C.W.G. International Penguin Conservation Work Group, 2002. Disponível em: HTTP://www.penguins.cl/magellanic-penguins.htm. Acessado em: 10 fev. 2017.

PETRY, M.V.; SCHERER, J.F.M.; SCHERER, A.L. Ocorrência, alimentação e impactos antrópicos de aves marinhas nas praias do litoral do Rio Grande do Sul, sul do Brasil. Rev. Bras. Ornitol., v.20, p.65-70, 2012.
RODRIGUES, T.M.A.; PALMEIRA, J.A.O.; MENDONÇA, J.T.M.; GOMES, O.M. Estudo evolutivo da anatomia das artérias coronárias em espécies de vertebrados com técnica de moldagem em acetato de vinil (vinilite). Rev. Bras. Circ. Cardiovasc., v.14, p.331-339, 1999.

SILVA-FILHO, R.P.; RUOPPOLO, V. Sphenisciformes (Pinguim). In: CUBAS, Z.S.; SILVA, J.C.R.; CATÃO-DIAS, J.L. (Eds.). Tratado de animais selvagens-medicina veterinária. Roca: São Paulo, 2006. p.309-323.

SOARES, G.L.; OLIVEIRA, D.; BARALDIARTONI, S.M. Aspectos da anatomia do coração do avestruz. Ars Vet., v.26, p.38-42, 2010.

VOGEL, B.; SIEBERT, H.; HOFMANN, U.; FRANTZ, S. Determination of collagen content within picrosirius red stained paraffin-embedded tissue sections using fluorescence microscopy. MethodsX, v.2, p.124-134, 2015

WHITTAKER, P.; KLONER, R.A.; BOUGHNER, D.R.; PICKERING, J.G. Quantitative assessment of myocardial collagen with picrosirius red staining and circularly polarized light. Basic Res. Cardiol., v.89, p.397-410, 1994.

WILLIAMS, T.D. (Ed.). Bird families of the world the penguins. New York: Oxford University Press, 1995. 352p.

WYNEKEN, J. The anatomy of sea turtle. Washington: NOAA, 2001. 172p. (Techinical Memorandum NMFS-SEFS, Department of Commerce NOAA). 